\title{
The Relative Importance of Nitrogen vs. Moisture Stress May Drive Intraspecific Variations in the SLA-RGR Relationship: The Case of Picea mariana Seedlings
}

\author{
Philippe LeBel $^{1}$, Robert L. Bradley ${ }^{1}$, Nelson Thiffault ${ }^{1,2^{*}}$ \\ ${ }^{1}$ Centre d'étude de la forêt, Département de biologie, Université de Sherbrooke, Sherbrooke, Canada; ${ }^{2}$ Ministère des Ressources \\ naturelles du Québec, Direction de la recherche forestière, Québec, Canada. \\ Email: *Nelson.Thiffault@mrn.gouv.qc.ca
}

Received April $1^{\text {st }}$, 2013; revised May $1^{\text {st }}, 2013$; accepted June $1^{\text {st }}, 2013$

Copyright (C) 2013 Philippe LeBel et al. This is an open access article distributed under the Creative Commons Attribution License, which permits unrestricted use, distribution, and reproduction in any medium, provided the original work is properly cited.

\begin{abstract}
Plants acclimate to nitrogen $(\mathrm{N})$ or moisture stress by respectively increasing photosynthetic $\mathrm{N}$ use efficiency (PNUE) or water use efficiency (WUE), in order to maximize their relative growth rate (RGR). These two phenotypic adaptations have opposite effects on specific leaf area (SLA). Thus, intraspecific variations in the SLA-RGR relationship should reflect the relative importance of $\mathrm{N}$ vs. moisture stress in plants. In this study, we measured needle gas exchanges and N concentrations in order to derive PNUE and WUE, as well as SLA and RGR of black spruce (Picea mariana) seedlings growing on a rapidly drained site in the presence or absence of Kalmia angustifolia. The eradication of Kalmia had resulted in a $140 \%$ increase in seedling growth over a 6 year period. We found a negative SLA-RGR relationship where Kalmia had been eradicated, and a positive one where Kalmia had been maintained. Kalmia eradication resulted in higher WUE when measurements were made directly on the seedlings, and in lower PNUE when twigs were rehydrated prior to gas exchange measurements. Our data suggest that the bigger seedlings on Kalmia-eradicated plots increase RGR by decreasing SLA, as a means of coping with moisture stress. By contrast, increasing SLA on noneradicated plots may be a means of coping with nutrient stress exerted by Kalmia. The SLA-RGR relationship could potentially be used to identify the limiting resource for black spruce seedlings in different environments.
\end{abstract}

Keywords: Black Spruce (Picea mariana); Kalmia angustifolia; Moisture and Nitrogen Stress; PNUE and WUE, SLA-RGR Relationship

\section{Introduction}

Variations in a given plant trait can be attributed to interspecific differences arising from natural selection, or to intraspecific variations arising from phenotypic plasticity in response to environmental conditions. As a general rule, species that compete well in resource-poor environments have lower relative growth rates (RGR) than those that grow in resource-rich environments [1]. This is partly because leaf attributes that favour leaf longevity and nutrient conservation also tend to diminish specific leaf area (SLA). Although there is some debate as to whether SLA directly affects RGR [2], the positive correlation between these two traits remains fairly consistent across species (e.g. [3]). Within a given species, however, the relationship between RGR and SLA is not as robust,

${ }^{*}$ Corresponding author. as studies have found these two traits to correlate either negatively [4], positively [5], or not at all [6]. Elucidating the mechanisms that control intraspecific differences in the SLA-RGR relationship is important for understanding how species acclimate across environmental gradients.

For many plant species, the environmental gradients that most affect RGR are the variations in soil nitrogen (N) supply or soil water availability. Plants may acclimate to $\mathrm{N}$ deficiency by increasing photosynthetic $\mathrm{N}$ use efficiency (PNUE) [7], whereas they may acclimate to moisture deficiency by increasing water use efficiency (WUE) [8]. High SLA results in low internal shading and low $\mathrm{CO}_{2}$ diffusion limitations [9] in the leaf, which increases PNUE. Hence, individuals growing in $\mathrm{N}$ poor environments can improve RGR by increasing SLA. However, higher SLA results in greater leaf transpiration $(E)$, 
thereby increasing sensitivity to water stress. Water limitations thus tend to reduce SLA [10], which leads to a greater WUE [11]. Hence, plants growing in water deficient environments can improve RGR by decreasing SLA. We thus hypothesized that intraspecific variations in the SLA-RGR relationship are due to the relative importance of soil $\mathrm{N}$ deficiency versus soil moisture deficiency.

In order to test our hypothesis, we performed an experiment where we measured SLA and RGR of black spruce (Picea mariana (Mill.) B.S.P.) seedlings that had been growing on a rapidly drained site in the presence or absence of Kalmia angustifolia L. (referred to hereafter as Kalmia) for 6 - 7 years. Ericaceous species such as Kalmia are known to induce a "growth check" on regenerating conifers that can last several decades [12]. Indeed, previous work on these plots had shown that Kalmia induced severe $\mathrm{N}$ deficiencies to black spruce seedlings [13]. Kalmia removal, on the other hand, resulted in a dramatic increase in black spruce growth and possible moisture limitations. In order to corroborate our hypothesis, we performed leaf gas exchange measurements directly on the seedlings, as well as on twigs that had been re-hydrated to alleviate the influence of water stress on stomatal conductance. We also measured needle $\mathrm{N}$ concentrations and growth. Thus, the relationship between needle $\mathrm{N}$ concentration and photosynthesis $(A)$, and between leaf transpiration $(E)$ and photosynthesis, allowed us to discuss the observed variations in the SLARGR relationship in terms in PNUE and WUE.

\section{Materials and Methods}

\subsection{Study Area}

The study was conducted on a clearcut site near Senneterre, Québec, Canada ( $\left.48^{\circ} 29^{\prime} \mathrm{N}, 76^{\circ} 55^{\prime} \mathrm{W}\right)$, in the balsam fir (Abies balsamea (L.) Mill.) — paper birch (Betula papyrifera Marsh.) bioclimatic domain, as described by [14]. Mean annual temperature is $2.5^{\circ} \mathrm{C}$, mean annual precipitation is $950 \mathrm{~mm}$, and the growing season is typically 150 - 160 days long. The soil is a Humo-Ferric Podzol, which formed on a rapidly drained fluvioglacial deposit [15]. At time of harvest, a forest floor humus layer $(\sim 8 \mathrm{~cm})$ overlaid the loamy sand mineral horizons. The previous stand, mainly composed of black spruce and jack pine (Pinus banksiana Lamb.), originated from a wildfire and was 70 years old when harvested in the summer of 1999. Kalmia dominated the remnant vegetation, which also included other ericaceous shrubs (Vaccinium spp.) and lichens (Cladina spp.).

\subsection{Experimental Design}

Our study was performed on plots that had previously been established to study the effects of Kalmia removal and fertilization on the growth performance of black spruce seedlings [16]. These 2 experimental factors had been tested using a replicated $(n=10)$ randomized split-plot design. Each replicate block comprised two main plots $(5 \mathrm{~m} \times 6 \mathrm{~m})$ separated by a 2-m buffer. In one main plot, Kalmia was eradicated in September 1999 through the application of an aqueous solution of $2 \%$ glyphosate herbicide (Monsanto Inc., Winnipeg, Canada) $+0.25 \%$ Sylgard $309^{\circledR}$ surfactant (Dow Corning Corp., Midland, MI). From 2000 to 2007, Kalmia resprouting in these plots was manually removed. Kalmia was kept undisturbed in the other main plot. In Oct. 2007, Kalmia cover averaged $30 \%$ and was $\sim 25 \mathrm{~cm}$ in height. Each main plot was divided into two subplots $(5 \mathrm{~m} \times 3 \mathrm{~m}$ ) in which we planted, in June 2000, 10 containerized 1-y-old black spruce seedlings ( $28.7 \mathrm{~cm} \pm 4.2 \mathrm{~cm}$ height; $3.3 \mathrm{~mm}$ $\pm 0.5 \mathrm{~mm} \mathrm{dia}$.) at $1 \mathrm{~m}$ spacings within a $2 \times 5$ grid. At time of planting, one subplot received $9 \mathrm{~g}$ of polymercoated slow-release N-P-K (26-12-6) fertilizer in a SilvaPak teabag (Reforestation Technologies International, Salinas, CA) buried $5 \mathrm{~cm}$ deep and $2 \mathrm{~cm}$ to the side of each seedling. The second subplot was left unfertilized. Five seedlings in each subplot were tagged for long-term growth measurements, whereas the remaining seedlings were used for sampling.

In 2006 and 2007, daily rainfall on the site was measured and recorded on a data logger (CR-10, Campbell Scientific Inc., Logan, UT).

\subsection{RGR and SLA}

For our study, the 3 hours allotted for mid-morning gas exchange measurements restricted our sampling to 6 randomly chosen replicate blocks. In October 2005, 2006, and 2007, we measured the height of tagged seedlings in each of the 24 subplots in these 6 blocks. From these measurements, we calculated the relative growth rate $(\mathrm{RGR}=(\ln$ height $[\mathrm{X}]-\ln$ height $[\mathrm{X}-1]) /($ time $[\mathrm{X}]-$ time [X - 1])) [17] of seedlings for 2006 and 2007. In October 2006 and 2007, 1 twig of current year needles was collected from the upper third portion of 3 untagged seedlings in each subplot. With these twigs, we determined needle total surface area for each subplot using the WinSEEDLE optical image analysis system (Régent Instruments, Quebec City, Québec). Needles were then weighed for fresh mass, freeze-dried and reweighed for dry mass. SLA was calculated by dividing leaf area by the dry mass.

\subsection{Needle Gas Exchange Trials and Needle N Concentrations}

In 2006, needle gas exchange measurements (i.e., pho- 
tosynthesis $(A)$ and transpiration $(E)$ ) were performed on 3 dates (10 July, 7 August, 12 September), each time on 1 current year twig located in the upper third portion of 1 randomly selected seedling in each subplot. Measurements were carried out under saturating light conditions $\left(1000 \mu \mathrm{mol}\right.$ photons $\left.\cdot \mathrm{m}^{-2} \cdot \mathrm{s}^{-1}\right)$ using a portable Lcpro + open-path photosynthetic system (ADC BioScientific Ltd., Great Amwell, UK). Light was provided by mixed red/blue light emitting diodes (LED) within a chamber specifically designed for conifer needles. Ambient $\mathrm{CO}_{2}$ concentration was maintained at $378 \pm 2 \mu \mathrm{mol} \mathrm{CO}_{2} \mathrm{~mol}^{-1}$. Measurements were carried out between 8:30 and 11:30 a.m. under sunny or partially cloudy conditions. Following measurements, twigs were excised and ovendried at $65^{\circ} \mathrm{C}$ for $48 \mathrm{~h}$, and needles were removed and weighed. Dry needles were then ground to pass through a 40-mesh screen, and a $200 \mathrm{mg}$ subsample was digested at $340^{\circ} \mathrm{C}$ in a $\mathrm{H}_{2} \mathrm{SO}_{4} / \mathrm{H}_{2} \mathrm{O}_{2} / \mathrm{Se}$ mixture [18]. Total Kjeldahl$\mathrm{N}$ in the digests was determined colorimetrically using a Lachat Quichem flow-injection analyzer (Zwellenger Instruments Inc., Milwaukee, WI).

In 2007, needle gas exchange measurements were again performed on 3 dates (3 July, 7 August, 6 September), this time using excised and rehydrated shoots to alleviate the influence of water stress on stomatal conductance [19]. One twig was thus clipped from the upper one-third portion of a randomly selected seedling in each subplot, placed in a water-filled vial and left to rehydrate for 30 min prior to $A$ and $E$ measurements. Preliminary tests had shown that excised and rehydrated shoots maintained optimal gas exchange for $2 \mathrm{~h}$ after excision.

\subsection{Statistical Analyses}

The effects of Kalmia, fertilizer, sampling year (when applicable) and their interaction terms on seedling height, RGR and SLA were tested using 2 or 3-way ANOVAs based on mixed model procedures. Given the lack of a significant fertilizer effect on RGR, SLA, foliar N and $E$ (see results), data were pooled across fertilization treatments before regressing RGR against SLA, and before regressing foliar $\mathrm{N}$ and $E$ against $A$. For both gas exchange experiments (i.e., measurements made directly on seedlings, and measurements made on rehydrated twigs), we used mixed model regression analyses to test the equality of slopes and intercepts of each Kalmia treatment for foliar $\mathrm{N}$ against $A$, and for $E$ against $A$. When warranted (see results), we compared these slopes and intercepts within each sampling date.

We considered blocks, sampling dates and sampling years as random effect variables. Post hoc comparisons of significantly different means were performed using Tukey's HSD test. Before each analysis, we checked ANOVA assumptions using Shapiro-Wilk's normality test and standard graphical approaches. We performed all analyses using the MIXED procedure of SAS 9.3 (SAS Institute, Cary, NC). Unless otherwise stated, $P<0.05$ was used as the threshold of significance.

\section{Results}

Seedlings growing in Kalmia-eradicated plots were significantly taller ( $140 \%$ ) than those in plots where Kalmia had been maintained (Table 1). Likewise, seedlings in fertilized plots were significantly taller ( 20\%) than those in non-fertilized plots.

SLA was significantly lower $(P=0.011)$, and RGR was marginally higher $(P=0.060)$, in plots where Kalmia had been removed compared to plots where Kalmia had been maintained (Figure 1). In both years, there was no significant Kalmia $\times$ fertilization interaction $(P>0.414)$, nor any fertilization effect $(P>0.265)$, on either SLA or RGR. Consequently, data were pooled across fertilization treatments in order to explore the effect of Kalmia on the SLA-RGR relationship. We thus found a significant negative relationship between SLA and RGR in plots where Kalmia had been removed, but a significant positive relationship between these two traits in plots where Kalmia had been maintained (Figure 1).

Treatments had no effect on foliar $\mathrm{N}$ concentrations and $E$. In both gas exchange experiments, there were significant positive relationships between foliar $\mathrm{N}$ and $A$, and between $E$ and $A$. When gas measurements were made directly on the seedlings, Kalmia removal had no effect on PNUE (i.e., on the slope of the foliar $\mathrm{N}$ vs. A relationship) (Figure 2(a)) nor on WUE (i.e., on the slope of the $E$ vs. A relationship). However, when WUE

Table 1. The effects of Kalmia angustifolia removal and fertilization on the mean height of Picea mariana seedlings planted in 2000 on a rapidly drained clearcut site in Northwestern Québec (Canada). Values in parentheses represent 1 Std. Error $(n=6)$.

\begin{tabular}{lcc}
\hline \multicolumn{1}{c}{ Treatment } & $\begin{array}{c}\text { Height in 2006 } \\
(\mathrm{cm})\end{array}$ & $\begin{array}{c}\text { Height in 2007 } \\
(\mathrm{cm})\end{array}$ \\
\hline Kalmia $\times$ fertilization $(P$-value $)$ & 0.885 & 0.827 \\
Kalmia maintained & $66.2(5.3)$ & $69.4(6.5)$ \\
Kalmia removed & $157.8(5.5)$ & $170.0(6.5)$ \\
$P$-value & $<0.001$ & $<0.001$ \\
Without fertilization & $102.2(4.4)$ & $109.0(5.1)$ \\
With fertilization & $121.9(4.3)$ & $130.4(5.1)$ \\
$P$-value & $<0.001$ & $<0.001$ \\
\hline
\end{tabular}




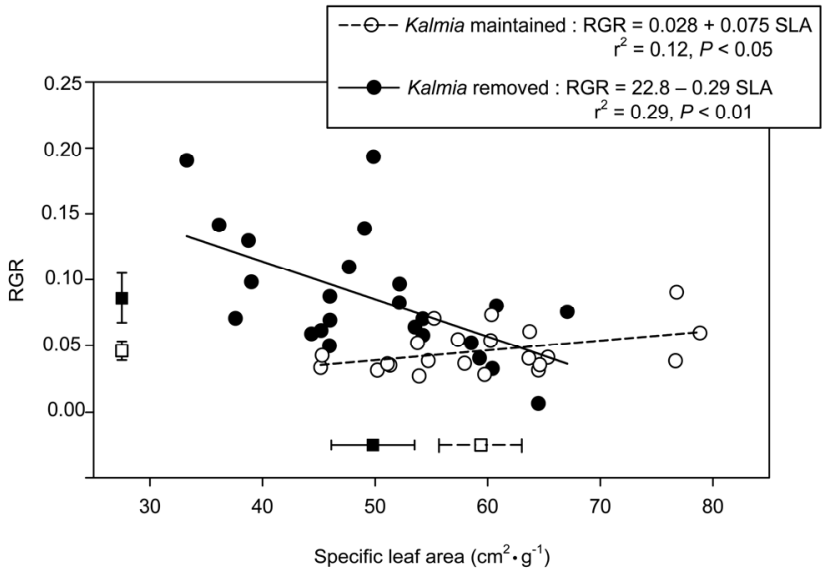

Figure 1. Relationship between specific leaf area (SLA) and relative growth rate (RGR) of Picea mariana seedlings growing since 2000 in the presence or absence of Kalmia angustifolia on a rapidly drained clearcut site in Northwestern Québec (Canada). Data are pooled across fertilizer treatments and sampling years (2006 and 2007). Squares and error bars along the $X$ and $Y$ axes represent treatment means ( \pm 1 Std. Error) for SLA and RGR, respectively.

was calculated for each sampling date, the differences in WUE between Kalmia treatments were progressively more significant as rainfall in the 10 days prior to measurements decreased (Table 2 and Figure 2(b)). When twigs were rehydrated prior to gas exchange measurements, PNUE was higher in plots where Kalmia had been maintained (Figure 3(a)), although the difference was marginally non-significant $(P<0.10)$. When twigs were rehydrated prior to gas exchange measurements, Kalmia removal had no effect on WUE (Figure 3(b)).

\section{Discussion}

Our data show that the presence of Kalmia will significantly affect the relationship between SLA and RGR for black spruce seedlings. The eradication of Kalmia resulted in bigger black spruce seedlings, perhaps as a result of lower interspecific competition for soil nutrients. Bigger seedlings could result, however, in greater moisture stress because of higher total water demand and transpiring surface area $[20,21]$. This is corroborated by the increasing differences in the slopes relating $E$ vs. A (i.e. WUE) as the amount of rainfall prior to measurements decreased (intra-annual comparison). It is further corroborated by the fact that Kalmia eradication resulted in higher WUE when gas exchange measurements were made directly on the seedlings, but not when twigs were first rehydrated to alleviate moisture stress (inter-annual comparison). We propose, therefore, that the bigger seedlings growing on Kalmia eradicated plots produced needles with a lower SLA as a means to increase WUE, in order to cope with

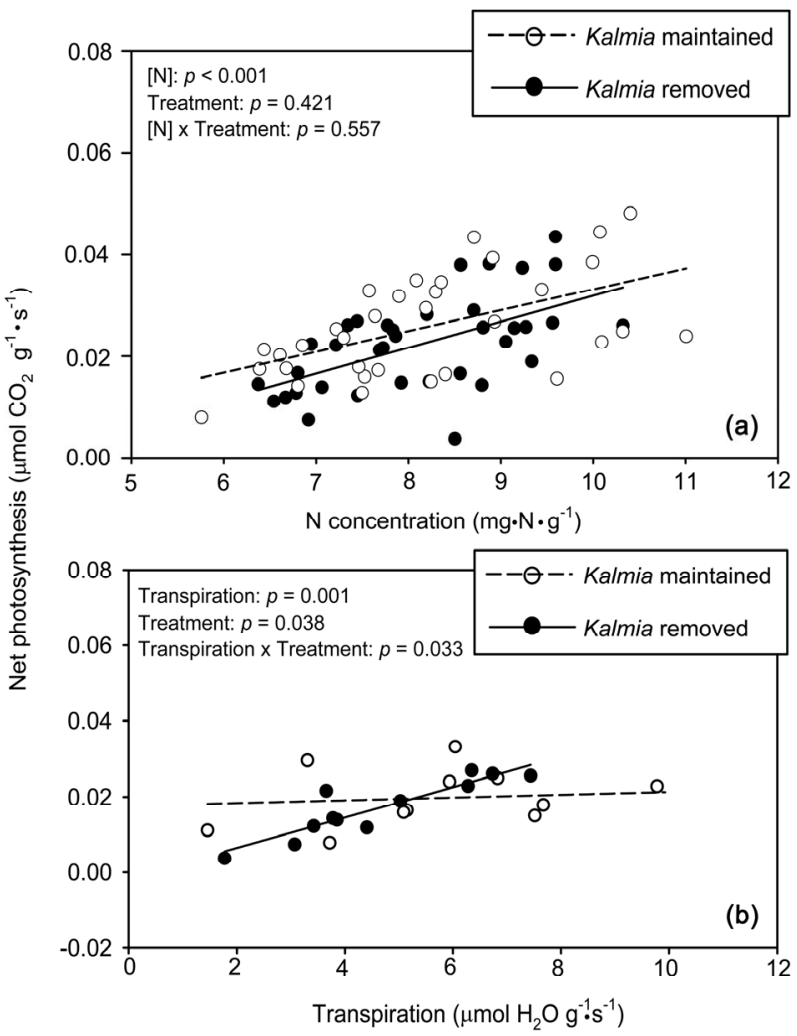

Figure 2. Relationships between foliar $\mathbf{N}$ concentration and net photosynthesis (frame (a)), and between transpiration rate and net photosynthesis (frame (b)), using gas exchange measurements performed directly on Picea mariana seedlings growing since $\mathbf{2 0 0 0}$ in the presence or absence of $\mathrm{Kal}$ mia angustifolia on a rapidly drained clearcut site in Northwestern Québec (Canada). In frame (b), only data from the driest sampling date (Sept. 2006) were used (see Table 2). In the top left corner of each frame, a significant interaction between the variable reported on the abscissa and Kalmia treatments indicates that the two slopes (i.e., photosynthetic $\mathrm{N}$ use efficiency, PNUE; or water use efficiency, WUE) are significantly different.

Table 2. Amount of precipitation in the $\mathbf{1 0}$ days prior to each sampling date (i.e., a proxy for soil moisture) at which gas exchange measurements were made directly on Picea mariana seedlings growing in the presence or absence of Kalmia angustifolia on a rapidly drained clear cut site in Northwestern Québec (Canada). P-values associated to the Kalmia $\times E$ interaction denote whether or not seedlings' water use efficiency (WUE) is significantly different in each Kalmia treatment.

\begin{tabular}{lcc}
\hline $\begin{array}{c}\text { Sampling date } \\
\text { in 2006 }\end{array}$ & $\begin{array}{c}\text { Precipitations within 10 } \\
\text { days prior to sampling (mm) }\end{array}$ & $\begin{array}{c}P \text {-value of the } \\
\text { Kalmia } \times \text { E interaction }\end{array}$ \\
\hline July 10 & 48.9 & 0.722 \\
August 7 & 36.5 & 0.098 \\
September 12 & 12.9 & 0.033 \\
\hline
\end{tabular}




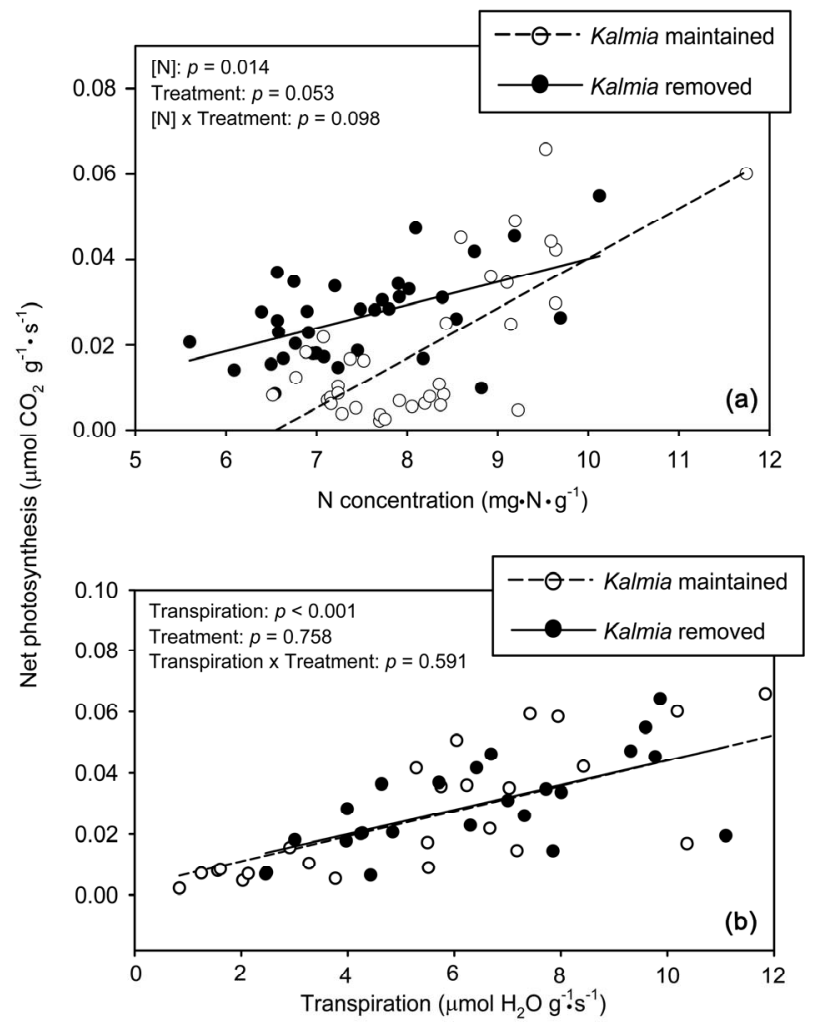

Figure 3. Relationships between foliar $\mathbf{N}$ concentration and net photosynthesis (frame (a)), and between transpiration rate and net photosynthesis (frame (b)), using gas exchange measurements performed on rehydrated twigs of Picea mariana seedlings growing since 2000 in the presence or absence of Kalmia angustifolia on a rapidly drained clearcut site in Northwestern Québec (Canada). In the top left corner of each frame, a significant interaction between the variable reported on the abscissa and Kalmia treatments indicates that the two slopes (i.e., photosynthetic $\mathbf{N}$ use efficiency, PNUE; or water use efficiency, WUE) are significantly different.

higher moisture stress [8]. The negative SLA-RGR relationship on Kalmia eradicated plots thus suggests that moisture stress is a growth-limiting factor for the bigger, more water-demanding, black spruce seedlings on these rapidly drained soils.

Seedlings that were kept in check by the presence of Kalmia were smaller and displayed lower moisture stress (i.e. lower WUE) than those on eradicated plots. Several studies have linked Kalmia-induced growth check of black spruce seedlings to mechanisms that reduce soil mineral $\mathrm{N}$ availability. For example, Kalmia litter may contain $>20 \%$ (dry mass) condensed tannins, which once released in the soil may form stable cross-links with proteins and prevent them from mineralizing $N[22,23]$. Higher $\mathrm{N}$ deficiency on the plots where Kalmia was maintained is corroborated by the linear relationships that were found between needle $\mathrm{N}$ concentration vs. A
(Figures 2(a) and 3(a)), whose slopes are a measure of PNUE. More specifically, maintaining Kalmia resulted in higher PNUE when gas exchange measurements were made on twigs that were first rehydrated, but not when measured directly on the seedlings. In other words, these smaller black spruce seedlings may also experience moisture stress on rapidly drained soils, but the presence of Kalmia creates additional growth-limiting soil nutrient stress that is apparent once moisture stress has been reduced or alleviated. Thus, a positive SLA-RGR relationship on plots where Kalmia was maintained suggests that the costs of having high SLA during periods of water stress are offset by the benefits of higher SLA in a nutrient poor soil environment.

Our reasoning relies partly on an inter-annual comparison of WUE across different rainfall periods, and partly on a comparison of gas exchange measurements made directly on seedlings to those performed on excised twigs that were then rehydrated. Given that each of these 2 sampling methods was used in a different year, it could be argued that the observed differences between the experiments were simply the result of physiological differences between sampling years. While this explanation cannot be discounted, we believe that it is unlikely to be the case. For example, seedling size is a good proxy for the physiological stage of black spruce seedlings [24]. In this respect, the difference in seedling size between sampling years was very small in comparison to that between Kalmia treatments, suggesting that the physiological response of seedlings to different leaf gas exchange measurements was mainly due to Kalmia removal affecting seedling size. This then raises the question of whether the differences we observed in the SLA-RGR relationship between Kalmia treatments is a typical feature in the ontogenic development of black spruce seedlings, regardless of environmental factors? Our experiment does not provide data to contradict this alternative explanation, but unpublished data collected by the Ministère des Ressources naturelles on Québec's North Shore, where annual rainfall is ca. $25 \%$ higher than at our study site, do provide some insight. More specifically, these data reveal no significant effect of SLA on RGR for $140-180 \mathrm{~m}$ tall black spruce seedlings growing on Kalmia eradicated plots with higher rainfall (N. Thiffault - unpublished results). We suggest, therefore, that future research provide more empirical support to our interpretation of the data, by performing a similar study that includes an irrigation treatment designed to alleviate moisture stress on Kalmia eradicated plots.

When making interspecific comparisons, correlated plant traits reveal trade-offs that define a species' nichedriven life history strategy. For example, species with small seeds tend to have a higher RGR than plants with 

in the SLA-RGR Relationship: The Case of Picea mariana Seedlings

larger seeds, because the former are associated to a ruderal lifestyle while the latter are adapted to stress conditions [25]. Thus, we expect robust correlations among plant functional traits when making broad comparisons across contrasting species. Such may not be the case, however, when making intraspecific comparisons. In our study, we found that the SLA-RGR relationship within a single species could be either positive or negative, depending on the presence or absence of a competitor. The supporting data suggest a phenotypic trade-off due to the relative importance of nutrient vs. moisture stress. We suggest, therefore, that the SLA-RGR relationship can potentially be used to identify the limiting resource for black spruce seedlings growing in different environments.

\section{Acknowledgements}

The authors thank J. Carignan, S. Lemay, É. Gaillard, A. Anctil, and M. Bergeron for technical assistance. We also thank I. Auger for statistical advice, and staff of the $L a-$ boratoire de chimie organique et inorganique, Ministère des Ressources naturelles du Québec (MRN) for analytical services. This study was funded by a NSERC Discovery Grant awarded to R. Bradley and MRN Project No 112310031.

\section{REFERENCES}

[1] R. Aerts, "Interspecific Competition in Natural Plant Communities: Mechanisms, Trade-Offs and Plant-Soil Feedbacks,” Journal of Experimental Botany, Vol. 50, No 330, 1999, pp. 29-37.

[2] Y. Osone, A. Ishida, and M. Tateno, "Correlation between Relative Growth Rate and Specific Leaf Area Requires Associations of Specific Leaf Area with Nitrogen Absorption Rate of Roots," New Phytologist, Vol. 179, No. 2, 2008, pp. 417-427.

doi:10.1111/j.1469-8137.2008.02476.x

[3] H. Lambers and H. Poorter, "Inherent Variation in Growth Rate between Higher Plants-A Search for Physiological Causes and Ecological Consequences,” Advances in Ecological Research, Vol. 23, 1992, pp. 187-261. doi:10.1016/S0065-2504(08)60148-8

[4] B. Li, J.-I. Suzuki and T. Hara, "Latitudinal Variation in Plant Size and Relative Growth Rate in Arabidopsis thaliana,” Oecologia, Vol. 115, No. 3, 1998, pp. 293-301. doi:10.1007/s004420050519

[5] P. Meerts and E. Garnier, "Variation in Relative Growth Rate and Its Components in the Annual Polygonum aviculare in Relation to Habitat Disturbance and Seed Size,” Oecologia, Vol. 108, No. 3, 1996, pp. 438-445. doi:10.1007/BF00333719

[6] A. Biere, "Intra-specific Variation in Relative Growth Rate: Impact on Competitive Ability and Performance of Lychnisflos cuculi in Habitats Differing in Soil Fertility," Plant and Soil, Vol. 182, No. 2, 1996, pp. 313-327.
[7] T. L. Pons, A. Van der Werf and H. Lambers, "Photosynthetic Nitrogen Use Efficiency of Inherently Slowand Fast-Growing Species: Possible Explanations for Observed Differences,” In: J. Roy and E. Garnier, Eds., A Whole-Plant Perspective of Carbon-Nitrogen Interactions, SPB Academic Publishing, The Hague, 1994, pp. 61-77.

[8] M. G. Letts, K. N. Nakonechny, K. E. Van Gaalen and C. M. Smith, "Physiological Acclimation of Pinus flexilis to Drought Stress on Contrasting Slope Aspects in Waterton Lakes National Park, Alberta, Canada,” Canadian Journal of Forest Research, Vol. 39, No. 3, 2009, pp. 629-641. doi:10.1139/X08-206

[9] P. B. Reich, M. G. Tjoelker, M. B. Walters, D. W. Vanderklein and C. Bushena, "Close Association of RGR, Leaf and Root Morphology, Seed Mass and Shade Tolerance in Seedlings of Nine Boreal Tree Species Grown in High and Low Light,” Functional Ecology, Vol. 12, No. 3, 1998, pp. 327-338. doi:10.1046/j.1365-2435.1998.00208.x

[10] U. Niinemets, "Global-Scale Climatic Controls of Leaf Dry Mass Per Area, Density, and Thickness in Trees and Shrubs,” Ecology, Vol. 82, No. 2, 2001, pp. 453-469. doi:10.1890/0012-9658(2001)082[0453:GSCCOL]2.0.C $\mathrm{O} ; 2$

[11] K. R. Hultine and J. D. Marshall, "Altitude Trends in Conifer Leaf Morphology and Stable Carbon Isotope Composition,” Oecologia, Vol. 123, No. 1, 2000, pp. 32-40. doi:10.1007/s004420050986

[12] L. M. de Montigny and G. F. Weetman, "The Effects of Ericaceous Plants on Forest Productivity,” In: B. D. Titus, M. B. Lavigne, P. F. Newton and W. J. Meades, Eds., The Silvics and Ecology of Boreal Spruce, Canadian Forest Service, Forestry Canada, St. John's Newfoundland, 1990, pp. 83-90.

[13] P. LeBel, N. Thiffault and R. L. Bradley, “Kalmia Removal Increases Nutrient Supply and Growth of Black Spruce Seedlings: An Effect Fertilizer Cannot Emulate,” Forest Ecology and Management, Vol. 256, No. 10, 2008, pp. 1780-1784. doi:10.1016/j.foreco.2008.02.050

[14] J. P. Saucier, A. Robitaille and P. Grondin, "Cadre BioClimatique du Québec. Écologie Forestière,” In: R. Doucet, Ed., Manuel de Foresterie, 2nd Edition, Éditions Multimondes, Québec, 2009, pp. 186-205.

[15] Soil Classification Working Group, "The Canadian System of Soil Classification,” 3rd Edition, Agriculture and Agri-Food Canada, NRC Research Press, Ottawa, 1998.

[16] N. Thiffault, B. D. Titus and A. D. Munson, "Black Spruce Seedlings in a Kalmia-Vaccinium Association: Microsite Manipulation to Explore Interactions in the Field," Canadian Journal of Forest Research, Vol. 34, No. 8, 2004, pp. 1657-1668. doi:10.1139/x04-046

[17] R. Hunt, “Basic Growth Analysis,” Unwin Hyman, London, 1990.

[18] I. J. Walinga, J. van der Lee, V. J. G. Houba, W. van Vark and I. Novozamsky, "Plant Analysis Manual," Kluwer Academic Publishers, Dordrecht, 1995. doi:10.1007/978-94-011-0203-2

[19] A. K. Mitchell and T. M. Hinckley, "Effects of Foliar 
Nitrogen Concentration on Photosynthesis and Water-Use Efficiency in Douglas Fir,” Tree Physiology, Vol. 12, No. 4, 1993, pp. 403-410. doi:10.1093/treephys/12.4.403

[20] J. D. Stewart and P.-Y. Bernier, “Gas Exchange and Water Relations of 3 Sizes of Containerized Picea mariana Seedlings Subjected to Atmospheric and Edaphic WaterStress Under Controlled Conditions," Annals of Forest Science, Vol. 52, No. 1, 1995, pp. 1-9. doi:10.1051/forest:19950101

[21] R. Jobidon, L. Charette and P.-Y. Bernier, "Initial Size and Competing Vegetation Effects on Water Stress and Growth of Picea mariana (Mill.) BSP Seedlings Planted in Three Different Environments," Forest Ecology and Management, Vol. 103, No. 2-3, 1998, pp. 293-305. doi:10.1016/S0378-1127(97)00228-4

[22] G. D. Joanisse, R. L. Bradley, C. M. Preston and A. D. Munson, "Soil Enzyme Inhibition by Condensed Litter Tannins May Drive Ecosystem Structure and Processes: The Case of Kalmia angustifolia," New Phytologist, Vol. 175, No. 3, 2007, pp. 535-546. doi:10.1111/j.1469-8137.2007.02113.x

[23] G. D. Joanisse, R. L. Bradley, C. M. Preston and G. D. Bending, "Sequestration of Soil Nitrogen as Tannin-Protein Complexes May Improve the Competitive Ability of Sheep Laurel (Kalmia angustifolia) Relative to Black Spruce (Picea mariana)," New Phytologist, Vol. 181, No. 1, 2009, pp. 187-198. doi:10.1111/j.1469-8137.2008.02622.x

[24] M. S. Lamhamedi, P.-Y. Bernier, C. Hébert and R. Jobidon, "Physiological and Growth Responses of Three Sizes of Containerized Picea mariana Seedlings Outplanted with and without Vegetation Control," Forest Ecology and Management, Vol. 110, No. 1-3, 1998, pp. 13-23. doi:10.1016/S0378-1127(98)00267-9

[25] H. C. Muller-Landau, "The Tolerance-Fecundity TradeOff and the Maintenance of Diversity in Seed Size," Proceedings of the National Academy of Science, Vol. 107, No. 9, 2010, pp. 4242-4247. doi:10.1073/pnas.0911637107 